\title{
Objective Analysis of Sea-Level Winds and Pressures Derived from Simulated Observations of a Satellite Radar-Radiometer and Actual Conventional Data ${ }^{1,2}$
}

\author{
LEONARD M. DRUYAN \\ Dept. of Meteorology and Oceanography, New York University, and Goddard Institute for Space Studies, NASA
}

(Manuscript received 29 June 1971, in revised form 25 November 1971)

\begin{abstract}
A computer-based procedure is developed that combines a field of simulated satellite-derived wind speeds with a limited amount of conventional surface data so as to recover the surface pressure field and the vector wind field over the North Pacific Ocean. Wind speeds are determined from an objective analysis of high spatial density ship observations in order to simulate the anticipated output of a proposed satellite-mounted radar-radiometer system. The conventional surface data consist of sparse observations from ocean-going vessels, observations from several tropical stations, and boundary pressures from analyses over coastal areas.

The simulated speeds are combined with the conventional network for various spatial distributions of ship data. The average rms departure of sea-level pressure fields analyzed by deleting from $75-94 \%$ of the available ship observations from the maximum data analysis is from 3.0-4.0 mb. Comparison of the wind components implied by the isobaric patterns to those of the withheld ship observations yields average rms differences of from $8.7-9.4 \mathrm{kt}$ for a range of $75-94 \%$ data deletion.
\end{abstract}

\section{Introduction}

Moore and Pierson (1970) have proposed a pencil beam scanning microwave radar-radiometer for measuring sea-level winds above the ocean surface. Both the experimental and theoretical investigations now underway indicate that, since microwave radar backscatter is most sensitive to the high-frequency portion of the ocean spectrum, it is therefore dependent on the local wind speed. Moreover, Hollinger (1970) has indicated that passive microwave measurements of the sea surface may be used for an independent estimation of sea-level wind speeds.

Given the possibility of determining sea-level winds by remote sensing, the meteorological satellite would be the ideal platform for providing continuous large-scale aerial coverage of much of the ocean-atmosphere boundary. Present understanding does indicate, however, that observations over areas of heavy precipitation could not be made by these remote-sensing techniques, thus limiting the area of the total "observable" ocean.

Given an adequate knowledge of instrument capabibilities there still remains the task of integrating any forthcoming information with data from pre-existing networks. The numerical model developed in this study was tested using the Univac 1108 computer at the University Heights Medical Center facilities of New

${ }^{1}$ Contribution No. 110 of the Geophysical Sciences Laboratory, New York University

${ }^{2}$ From a thesis submitted in partial fulfillment for the $\mathrm{Ph} . \mathrm{D}$. degree, Department of Meteorology and Oceanography, New York Úniversity.
York University and the IBM 360/95 at the Goddard Institute for Space Studies. It combines hypothetical wind speed data of the quantity and distribution that would be forthcoming from a spacecraft-mounted, scanning pencil beam, microwave radar-radiometer [as proposed by Moore and Pierson (1970)] with observations of sea-level pressure and wind velocity from ocean-going vessels. The model generates sea-level pressure and wind fields from a minimum of conventional data such as might be available in real time over Southern Hemisphere oceans.

\section{Experimental design}

Fig. 1 shows the instrumentation proposed by Moore and Pierson. The pencil beam would scan from side to side about the satellite track for a total swath width of about $1200 \mathrm{~km}$. By making observations every $120 \mathrm{~km}$ across this scan, eleven observations would be made available for each scan. If one scan is completed every $120 \mathrm{~km}$ along the sub-satellite track, observations will be contiguous in the direction of the satellite motion as well as to either side.

The North Pacific Ocean was taken as the area for the study, and the orbital elements of a Nimbus satellite were used in the simulation of data described below. Fig. 2 shows the area of the study and the borders of the Cartesian grid network $(i, j)$ which was used.

Fig. 3 shows the aerial coverage (swaths) over the North Pacific Ocean that would have resulted if such a system had flown on Nimbus 2 on 15 May 1966. 


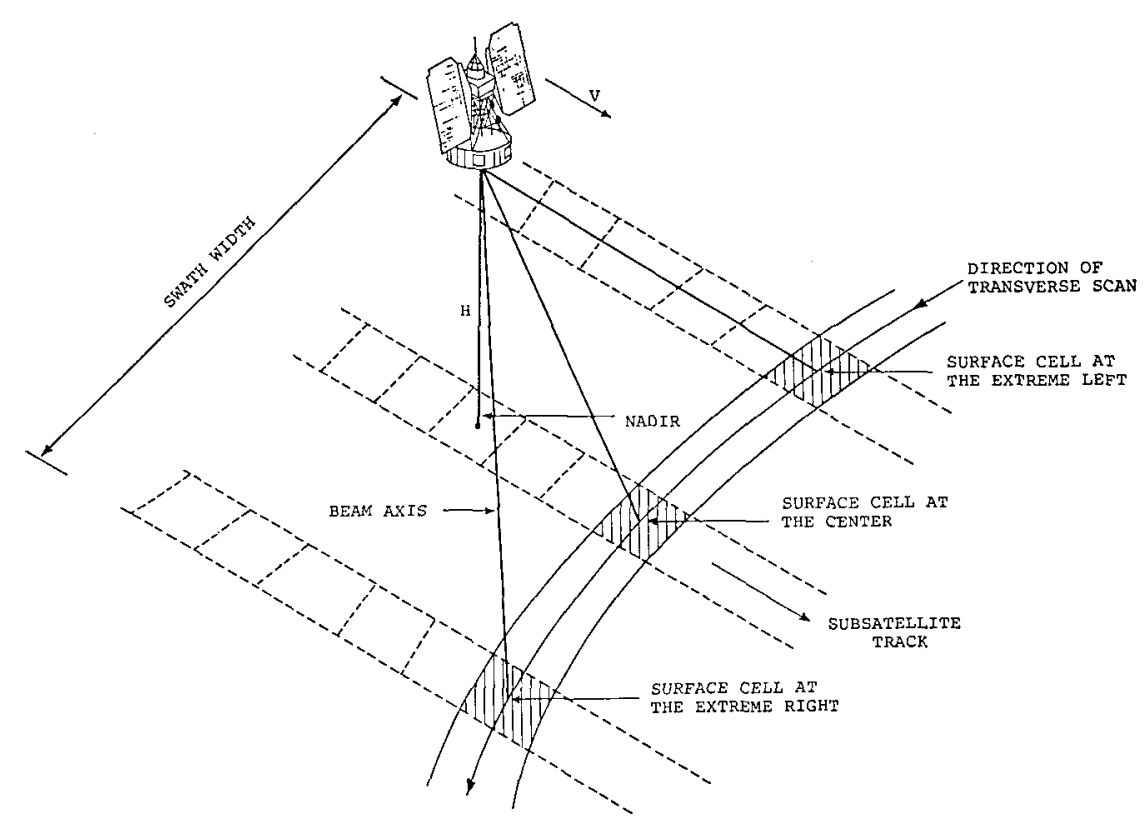

Fig. 1. Scan procedure for an operational spacecraft-mounted radar-radiometer system for sea-state measurements.

Wind speeds were simulated for each square that would have been illuminated by the pencil beam. This was accomplished by gathering a maximum of meteorological observations from non-real-time sources to supplement data normally available at synoptic map time. [A discussion of the availability and reliability of these data is found in Cardone (1969).] A horizontal interpolation of the wind field is carried out numerically according to Cardone's model of the marine boundary layer. Thus, very realistic speed values are made available for the areas of the map intercepted by the subsatellite swaths shown in Fig. 3.

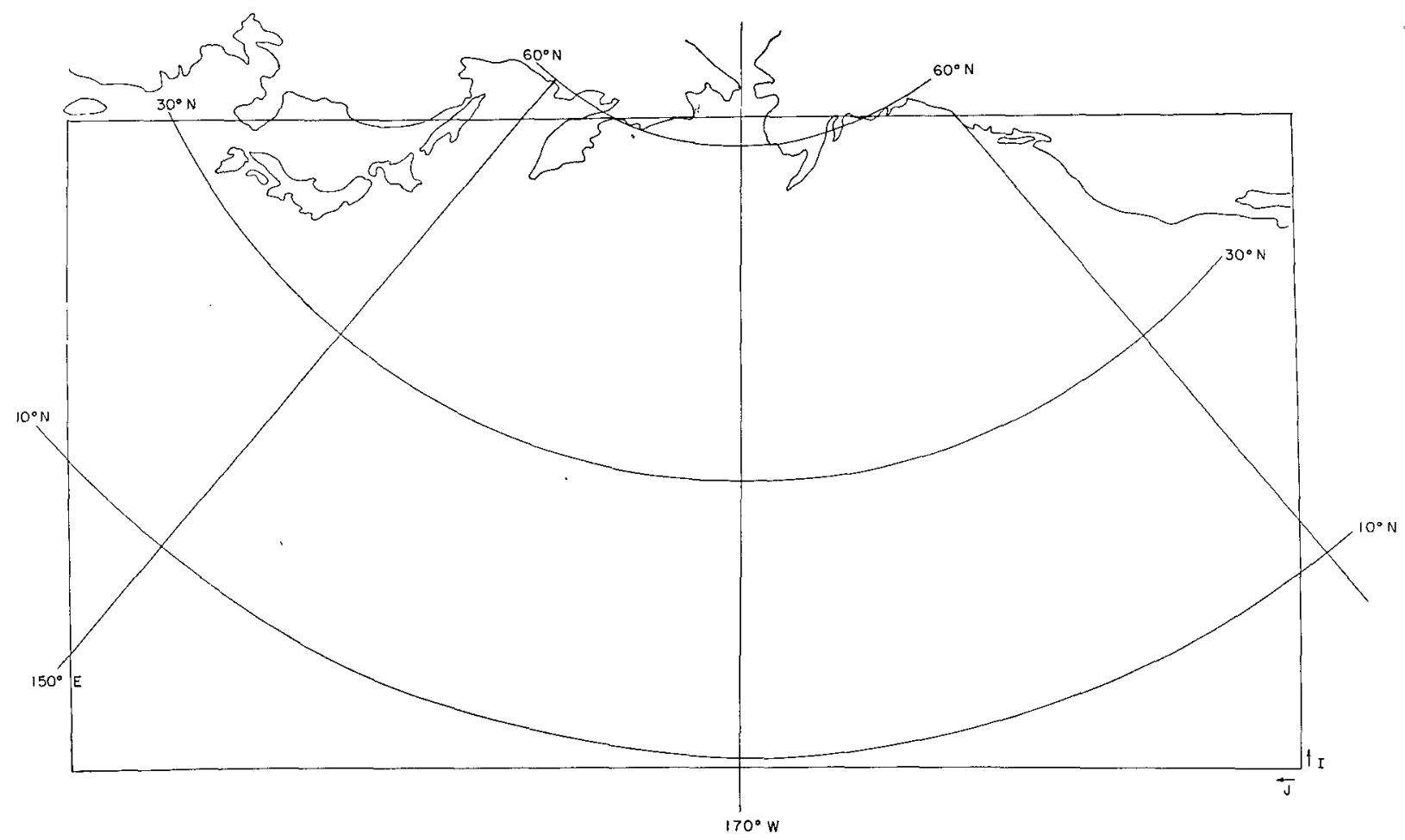

FIG. 2. Extent of area under study, the borders of the Cartesian grid system used, and the sign convention. 


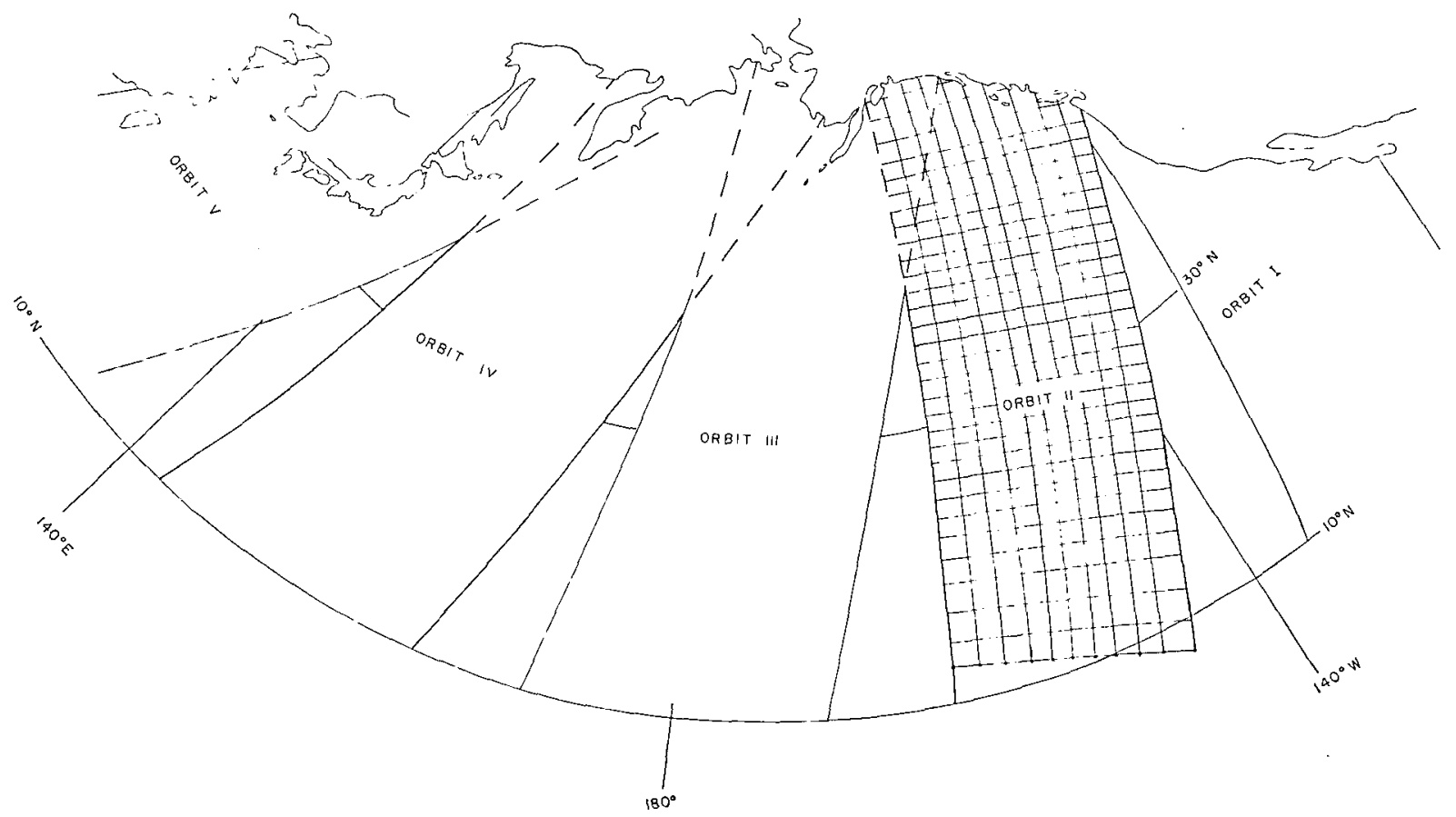

FIG. 3. Swaths over the North Pacific Ocean that would be illuminated by the satellite-mounted radar-radiometer. The density of observations is implied by the intersections within orbit II.

A Cartesian grid system was used for the analysis and for the model discussed below. Superposition of the grid on a polar stereographic projection of the Northern Hemisphere yields $100 \mathrm{n}$ mi separation between adjacent grid lines at $60 \mathrm{~N}$.

Since the density of the satellite wind speed observations is greater than that of the grid points, speeds are simulated for each sub-satellite square by curvilinear interpolation of the objective analysis.

After the satellite wind speeds are thus generated, the grid point values are erased from the computer memory, leaving only those observations that the satellite-mounted instrument would "see" and the raw data observed at each ship.

The meteorological data used in the study consist of approximately simultaneous observations; thus, the time variation of the wind speed, which actual satellite observations would reflect, is not accounted for. However, Jastrow and Halem (1970) have demonstrated how data from earth orbiting satellites can be used as continuous input to numerical weather prediction models; satellite-derived data replace the values predicted by the model at those grid points for which the satellite has provided information and at the time steps in the computations that correspond to the time of observation. Thus, future applications of the results of this study might see sections of the pressure and wind fields analyzed using satellite data corresponding to perhaps only one orbit per section. (A satellite swath from $80 \mathrm{~N}$ to the equator takes about $27 \mathrm{~min}$.)

Although ship data from real-time and non-real-time sources were needed to approximate the actual wind speed field, it was desirable to apply the model to situations of different data density. The wind and pressure fields generated with the maximum available ship data (150-500 ship observations) were considered as the standards against which the analyses at lower data densities could be verified. Verifications were computed relative to the "all-data" generated fields for onefourth, one-ninth and one-sixteenth the number of ships each, in combination with the satellite speeds generated as discussed above. One-fourth and one-ninth the original data density simulates the real-time data available in Northern Hemisphere oceans at different map times, while one-sixteenth the original data density will be similar to the available density of real-time data for the Southern Hemisphere oceans.

In later discussion of the model, therefore, the "ship data" refer just to those observations that were selected in order to achieve the desired data density. The specific ships were chosen for each sample by random selection from the complete listing.

Persistence often provides a realistic analysis of the sea-level pressure field in the tropics. On the other hand, extrapolating the mid-latitude pressure analysis to the tropics using wind-pressure relationships is a precarious venture. Unfortunately, the grid-by-grid persistence pressure values are not easily prepared for the computerized analysis. Therefore, eight permanent tropical stations are included and treated as ship data by each analysis. Some of them correspond to island observations, one to weather ship N, while the others were esti- 
TABLE 1. Regression equations for computation of the geostrophic wind speed from the actual wind speed at $19 \mathrm{~m}$ (units, knots), for various air-sea temperature differences and latitudes.

\begin{tabular}{lcc}
\hline \hline \multicolumn{1}{c}{ Equation } & $\begin{array}{c}\text { Air-sea } \\
\text { temperature } \\
\text { difference } \\
\left({ }^{\circ} \mathrm{C}\right)\end{array}$ & Latitude \\
\hline$U_{G}=1.77 U_{19.5}-7.15$ & $T D<-1$ & All \\
$U_{G}=1.91 U_{19.5}-5.97$ & $-1 \leqslant T D \leqslant 1$ & All \\
$U_{G}=3.00 U_{19.5}+7.65$ & $1<T D \leqslant 3$ & South of $18 \mathrm{~N}$ \\
$U_{G}=2.48 U_{19.5}+1.64$ & $1<T D \leqslant 3$ & $18 \mathrm{~N}-28 \mathrm{~N}$ \\
$U_{G}=2.33 U_{19.5}-3.32$ & $1<T D \leqslant 3$ & $28 \mathrm{~N}-38 \mathrm{~N}$ \\
$U_{G}=2.24 U_{19.5}-7.65$ & $1<T D \leqslant 3$ & North of $38 \mathrm{~N}$ \\
$U_{G}=2.10 U_{19.5}+34.4$ & $3<T D \leqslant 5$ & South of $28 \mathrm{~N}$ \\
$U_{G}=2.59 U_{19.5}+10.5+1.48(4-T D)$ & $3<T D \leqslant 5$ & $28 \mathrm{~N}-33 \mathrm{~N}$ \\
$U_{G}=2.62 U_{19.5}-2.70$ & $3<T D \leqslant 5$ & $33 \mathrm{~N}-48 \mathrm{~N}$ \\
$U_{G}=2.33 U_{19.5}-3.32$ & $3<T D \leqslant 5$ & North of $48 \mathrm{~N}$ \\
$U_{G}=2.10 U_{19.5}+34.4$ & $5<T D$ & South of $28 \mathrm{~N}$ \\
$U_{G}=2.59 U_{19.5}+10.5+1.48(4-T D)$ & $5<T D$ & $28 \mathrm{~N}-48 \mathrm{~N}$ \\
$U_{G}=2.62 U_{19.5}-2.70$ & $5<T D$ & North of $48 \mathrm{~N}$ \\
\hline
\end{tabular}

mated from the real-time NMC Northern Hemisphere analyses. An observation point was also included in the area of Los Angeles, Calif., because a considerable number of grid points lie over the western United States.

In order to integrate the marine analysis with the coastal pressure observed by continental stations, pressures are made available to the analysis along the northernmost $i$ grid line, and three horizontal rows of pressure are interpolated between these border values and those from within the analysis.

\section{The model}

Since the spatial coverage of the sub-satellite swaths is so great, it is possible to recover the entire wind speed field from the satellite observations and the ship observations of wind speed. Weighted averages of the simulated radar observed wind speeds are assigned to the grid points they are closest to; the weighting function is inversely proportional to the square of the distance of each observation from its grid point.

The resulting grid point distribution of speed values is changed slightly from the original input field because of the interpolations and averaging procedures discussed above. Also, small areas remain devoid of values because they are "missed" by the sub-satellite swath (Fig. 3).

Some additional grid points may receive values if there are any ship observations located outside of the swath areas. Those ship observations located within the swaths simply substitute their speed value for that derived by the satellite. In the simulation described here they are, of course, almost identical. If, in reality, they would differ, a meaningful priority would have to be established reflecting the knowledge of the radar system's capabilities versus the possible variation in the quality of ship data.

A scanning of the grid network locates those points that still lack a speed value; one is interpolated to any grid point by taking a weighted average of all values found within a certain radius, again weighting inversely as the square of the distance.

The magnitude of the sea-level pressure gradient can be computed from each wind speed at each grid point. However, in order to interpolate the pressure field to those areas between observations and beyond them, both the direction and magnitude of the pressure gradient must be known. Determining the orientation of the isobars thus becomes an important task of the model. Since wind direction is related to isobar orientation, except for some mesoscale departures, a specification of the sea-level pressure field can be used to infer wind direction, which, when combined with the available wind speeds, would define the total wind vector over the field.

Cardone's (1969) model of the marine boundary layer related the actual wind at $19.5 \mathrm{~m}\left(U_{19.5}\right)$ to the sea-level geostrophic wind speed $U_{G}$ (which corresponds to a given pressure-gradient magnitude). The ratio of the two winds $\left(U_{19.5} / U_{G}\right)$ depends on latitude and air-sea temperature difference (TD) as well as $U_{G}$ itself, and so $U_{19.5}$ is determined from a knowledge of the other three parameters by an iterative computation.

For the purposes of this study, it was desirable to determine $U_{G}$ and the inflow angle by specifying $U_{\mathbf{1 9 . 5}}$, $T D$ and latitude. An iterative scheme was therefore used to generate a wide range of values of $U_{19.5}$ vs $U_{G}$, and the inflow angle vs $U_{G}$, for a wide range of $T D$ and latitudes. Linear relationships were then derived for $U_{G}$ vs $U_{19.5}$, each one applicable over a range of $T D$ and latitude. The equations, listed in Table 1 , may be compared to those of Hasse and Wagner (1970) who derived similar equations based on data gathered over a twoyear interval at an observatory in the North Atlantic Ocean. In the application of the equations in Table 1, bounds were imposed on $U_{19.5} / U_{G}$ such that $0.15 \leqslant\left(U_{19.5} / U_{G}\right) \leqslant 0.9$.

The value of $U_{G}$, computed as described above, corresponds to the pressure gradient in straight flow that would have resulted in the wind speed $U_{19.5}$. It is desirable to determine the pressure gradient necessary to maintain the given wind speed in horizontally curved flow; the pressure gradient is larger for cyclonic and smaller for anticyclonic flow than it is in straight flow for a given wind speed. Thus, if $P G_{s}$ is the pressure gradient corresponding to a geostrophic wind $U_{G}$ (as determined by Table 1 ) and $P G_{c}$ the adjusted pressure gradient for horizontally curved flow, then

$$
\left.\begin{array}{r}
P G_{c}=P G_{s}+\left(U_{19.5}\right)^{2} / R, \\
\text { for cyclonic curvature } \\
P G_{c}=P G_{s}-\left(U_{19.5}\right)^{2} / R, \\
\text { for anticyclonic curvature }
\end{array}\right\}
$$

where $R$ is the radius of curvature of the air trajectory. 
In order to compute $R$, a time record of air movements is required. It is, however, more convenient to assume that the isobar curvature is representative of trajectory curvature so that an analysis of the instantaneous pressure field can be used in the computations. The pressure field is analyzed in the first iteration by using $U_{G}$ (Table 1) which neglects curvature; the curvature of the isobars thus generated is used in Eq. (1) to compute the adjusted pressure gradient which is then used in the computation of the second iteration. The curvature of an isobar can thus be determined from

$$
R=\frac{(\partial P / \partial y)^{2}\left\{1+[-(\partial P / \partial x) /(\partial P / \partial y)]^{2}\right\}^{\frac{1}{2}}}{\partial P / \partial x\left[2 \partial^{2} P / \partial x \partial y-(\partial P / \partial x)\left(\partial^{2} P / \partial y^{2}\right) /(\partial P / \partial y)\right]-(\partial P / \partial y)\left(\partial^{2} P / \partial x^{2}\right)},
$$

where $P$ is the sea-level pressure and $x$ and $y$ are orthogonal coordinates.

A single linear relationship was derived that computes inflow angle solely as a function of the ratio $U_{19.5} / U_{G}$; this ratio implicitly accounts for variation of inflow angle with $T D$. A small empirical adjustment allows for a slight variation of the inflow angle with latitude. The following equation represents a close linear fit to values of inflow angle obtained using Cardone's (1969) model over a wide range of $U_{19.5} / U_{G}$ and latitudes:

$$
\theta=-17.3\left(U_{19.5} / U_{G}\right)+26.5+0.04(L-35),
$$

where $\theta$ is the inflow angle and $L$ latitude, both in degrees.

Observations of sea-level pressure, wind speed and wind direction are supplied by ocean-going vessels. If the spatial density of pressure observations were great enough, a straightforward scalar interpolation might suffice to specify the entire pressure field. For a somewhat lower data density the pressure value at a grid point might be determined by correcting an initial guess field; the corrections would be determined by examining the wind and pressure observations at one or more ships within some scan radius of the grid point (see Cressman, 1959). However, according to typical data density situations of, say, the Southern Hemisphere oceans, the scan radius often must be a few thousands of miles in order to include even one ship. Under such circumstances, little can be done to improve the initial guess field.

The technique described in this study demonstrates how knowledge of the wind speed field can be used in conjunction with scattered conventional meteorological observations to interpolate the sea-level pressure field to areas largely devoid of observations of pressure.

A numerical "single-station" analysis is made about each ship, making maximum use of the data. The reported pressure determines the value of the isobar passing through the ship, the wind speed reflects the isobar spacing, and the wind direction indicates isobar orientation. The analysis is extended outward by allowing the isobars in the ship's" vicinity to separate or come together in accordance with the speed implied magnitude of the pressure gradient at the surrounding grid points. Thus, sections of the isobaric analysis are accomplished with considerable confidence corresponding to areas of influence about each ship.
The extent of each ship's area of influence must depend on the data density. The following discussion describes the computation of the maximum area used in this study. In those circumstances wherein a ship area is to be computed very close to a previously completed single-station analysis, the area of influence is diminished according to the distance between the ships.

Fig. 4 shows the relationship between various significant angles at a grid point. Note that an isobar makes an angle of $(\alpha+\omega+\theta)$ with the $j$ grid line, where $\alpha$ is
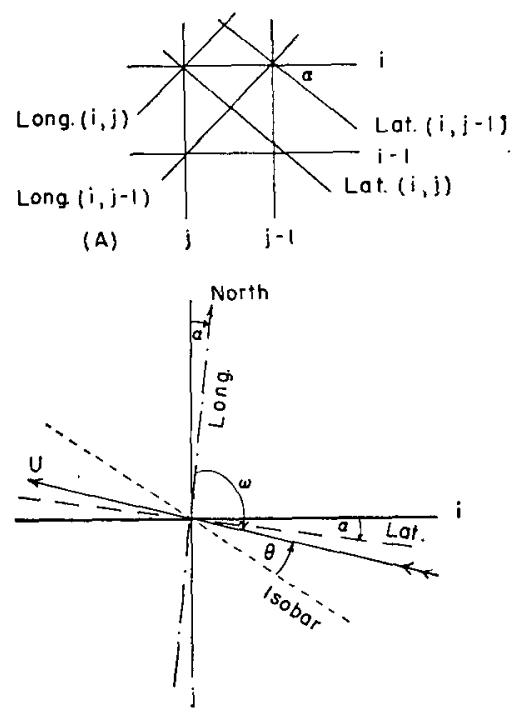

(B)

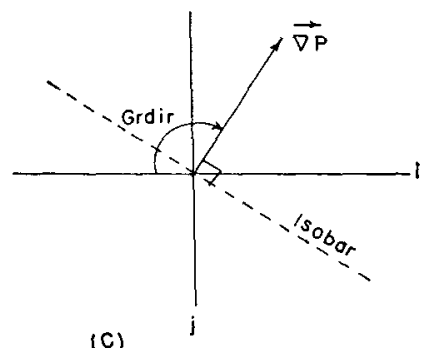

Fig. 4. Computations of $\alpha$, the angle between latitude lines and $i$ grid lines (A); the relationship (B) between various significant angles at a grid point [where $\theta$ is inflow angle (measured positive when wind blows toward lower pressure), $\alpha$ is measured positive clockwise from an $i$ grid line to intersecting lines of latitude, and $\omega$ is the wind direction measured positive clockwise from true north]; and the relationship (C) between_directions_of the pressure gradient, the isobar and the grid lines. 


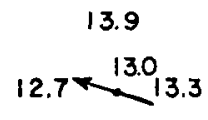

12.1

(A)

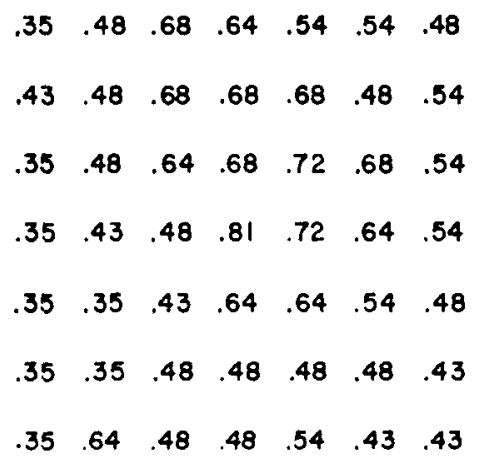

(C)

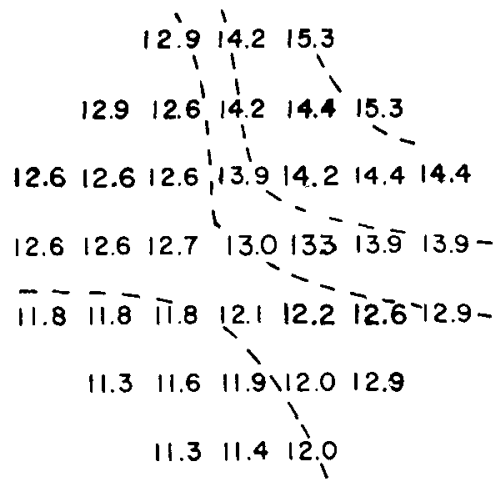

(E)

FIG. 5. Reconstruction of a single-station analysis illustrating computation of the pressures adjacent to a ship (A), wind speed ( $\mathrm{kt}$ ) at surrounding grid points (B), corresponding pressure gradients (mb per grid) for latitude $15 \mathrm{~N}$ (C), second state of single-station analysis (D), third state of single-station analysis $(E)$, and resulting analysis $(F)$, about ship observations (including smoothing). In all cases $1000 \mathrm{mb}$ has been subtracted from the pressures for clarity. the angle between the $j$ grid line and a line of longitude, $\omega$ the wind direction measured from true north, and $\theta$ the cross-isobar angle. The direction of the pressure gradient ( $\mathrm{Gr}$ Dir) is therefore also $(\alpha+\omega+\theta)$ degrees from the $i$ grid line.

Fig. 5 shows a reconstruction of a single-station analysis. The wind observation and the pressure at and adjacent to the ship location are given in panel (A). The wind speed (knots) has been plotted for each of the surrounding grid points in panel $(B)$ and the corresponding pressure gradient magnitudes (mb per grid) are in panel (C) (note that the ship was at $15 N$ ). Panels (D) and (E) show different stages of the pressure analysis in sequence. The tighter isobar spacing to the immediate northeast of the ship reflects the higher wind speeds, whereas the lower wind speeds have caused a wider spacing between adjacent isobars. Note that the five pressures represented in panel (A) have been constrained throughout the computations, but that other pressures have been allowed to change slightly as the gradient at each grid point undergoes mutual adjustment. Panel (F) shows this single-station analysis after it has been incorporated into a smoothed field.

The model makes use of present capabilities that 
allow accurate determination of the positions of low pressure centers. Continuity from previous analyses as well as interpretation of cloud photographs from meteorological satellites are the two most obvious techniques.

Foreknowledge of the location of the low pressure centers indicates, by definition, a pattern of pressures which increase radially outward. Thus, the direction of the pressure gradient is known at the center of each low pressure system. The initially symmetric isobar pattern is modified away from the center in a way similar to that discussed above with regard to the ships' area analyses. In this region, however, the value of each isobar is not known initially.

The value of each pressure minimum can be estimated from observations at nearby ships; should no data be available within the search area and should the low center be close to the upper boundary where land values of pressure are available, the central pressure can be estimated from this source of data.

If neither of these procedures is applicable, a central pressure must be determined by examining the pressure pattern generated about a more distant ship. The central pressure is assigned so that the pattern of increasing pressures away from the low is compatible with that generated by the single-station analysis.

The procedure creates such a background analysis by searching for the ship observation with the highest pressure reading in each of the four quadrants about each low system. The pattern of increasing pressures, whose orientation depends on the distribution of wind speeds, is thus determined in the area between the low center and the area of maximum pressure. A check of the wind direction at this ship can help avoid choosing one located on the far side of the high pressure ridge. The direction of the pressure gradient can then be reversed on the far side of the ship if it is desirable to extend the background analysis further.

The background analysis is a first guess that has thus been determined over the entire map. The large-scale analysis will be a suitable background upon which the other ships' single-station analyses may be superimposed. In order to insure continuity, values at the boundaries between these data patches and the background are determined by linear interpolation.

Fig. 6 shows the results of a sequence of computations near a low pressure center. The pressures computed in each step have been plotted at the grid points and the pressure gradient magnitudes on which the calculations have been based have been entered in parentheses.

The pressure field is smoothed in order to dampen what may be unrealistic small-wavelength perturbations. The smoothed value at a grid point is

$$
S(i, j)=[P(i, j)+b \bar{P}(i, j)] /(1+b),
$$

where $\bar{P}$ is the mean value of the pressures at the four adjacent grid points and $b$ is the smoothing parameter. The value of $b=1$ that was used in this study completely smooths wavelengths equal to two grid lengths. Experimentation showed that passing over the pressure field twice with the smoothing operator achieves the best results.

\section{Results}

In all, 280 sea-level wind and pressure fields were analyzed using the model. A given synoptic time was analyzed for four data-density situations and thus a total of 70 synoptic times are included. The maximum number of ship observations available for a given synoptic time varied between 150 and 500 . The analysis that used all of the data was the standard against which the sea-level pressure fields generated using a lower data density were compared.

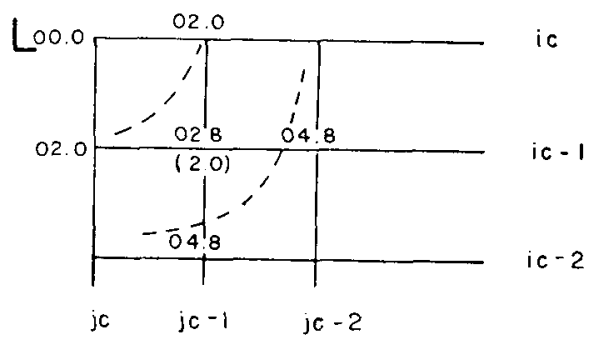

(A)

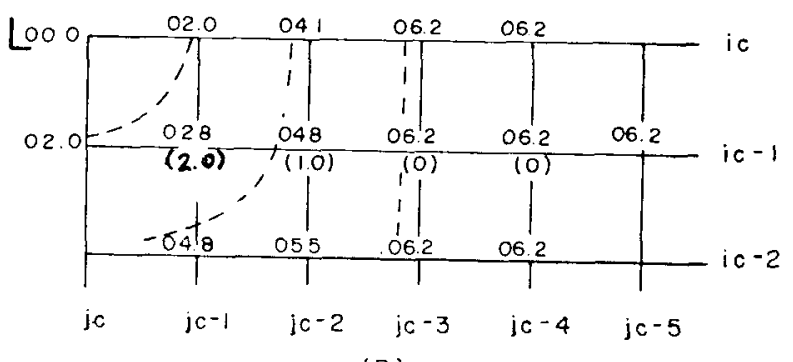

(B)

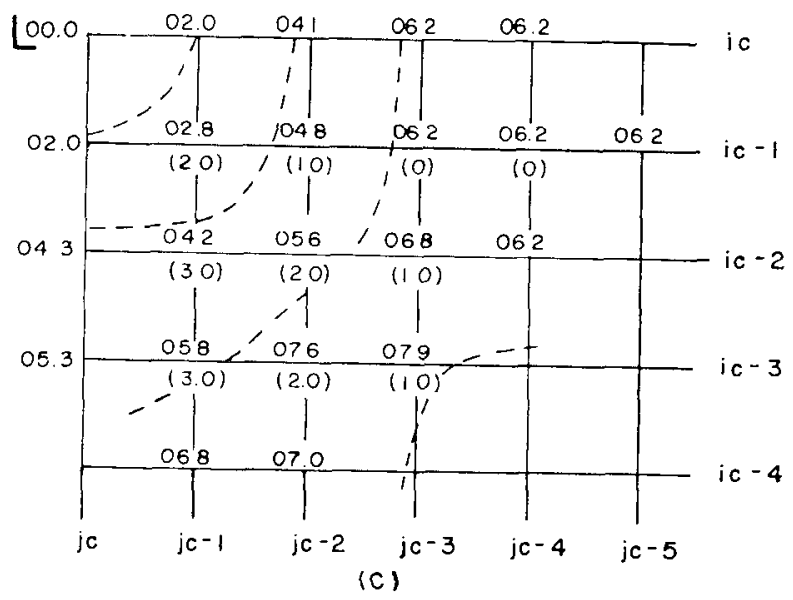

FIG. 6. Results of a sequence of computations near a low center (A), and continuation of the analysis (B,C). In all cases $1000 \mathrm{mb}$ has been subtracted from the pressures for clarity. The numbers in parentheses are pressure gradients (mb per grid). 
The rms of the pressure differences between the field at the lower data densities and the maximum data analysis was computed for each field as well as for sections of each. It was intended that these pressure differences be interpreted as expected values of analysis errors that will be encountered under operational circumstances when satellite wind speeds are available as a supplement to the usual density of real-time data over the oceans.

As expected, the rms pressure error increases as additional ships are withheld from the analysis. For those analyses that used about one-fourth as many ships (40100 ) as were available for the corresponding maximum data analysis, the average value of the rms pressure error was $3.0 \mathrm{mb}$; for those using one-ninth, the error was 3.5 $\mathrm{mb}$; while for those using one-sixteenth, it was $4.0 \mathrm{mb}$. The tropics usually showed the least error, about $2 \mathrm{mb}$, but this can be explained by the inclusion of the eight tropical stations for all the analyses as previously discussed.

The larger errors usually correspond to areas of very large pressure gradient. A given percentage error in the estimate of a large pressure gradient leads to large errors of pressure whereever the pattern is extrapolated over any significant distance away from known values.

The rms pressure errors may be compared to those encountered by Thomasell and Northrop (1970) in their objective analyses. Although their analysis procedure is completely independent of the model under discussion, it is nevertheless useful to note their results here because they also computed the rms pressure differences between fields analyzed at different data densities.

In one series of the study sea-level pressure fields were analyzed from pressure data of spatial density comparable to that used in the one-fourth maximum data category of this study. Their computations showed an rms pressure error of about $3.7 \mathrm{mb}$.

By way of contrast it should be mentioned that the availability of the simulated satellite wind speeds in this study was a decided advantage. On the other hand, their system defined perfect data points at fixed spatial intervals, some of which were deleted by random selection afterward, yielding about one data point for every 41 grid points. This procedure almost guarantees a fairly uniform distribution of perfect data, whereas this is often not the case in this study.

Wind directions were deduced from the isobaric pattern wherever a ship observation was available for comparison. These comparisons were made for the maximum data analyses where the observed winds and pressures were part of the input and also for the sparse data analyses where many of the ship observations were withheld. The orthogonal components of the wind vector implied by the isobar orientation were compared to the components of the observed wind.

For the maximum data analysis the isobar orientation near each ship, initially determined by the observed wind direction and the computed inflow angle, is modi- fied by smooth interpolation of the high-density pressure data. Hence, if the final analysis is considered realistic, it may be deduced that these rms wind component errors are due primarily to limitations in the ability to compute the inflow angle and to the uncertainty of the observed direction which is reported to the nearest $10^{\circ}$ of azimuth. These errors should and do increase when. ship observations are withheld, and the amount of this increase is a measure of the skill with which the model has interpolated the pressure pattern in sparse data areas; it is also a measure of the skill with which the pressure gradient has been deduced from the abundant. wind speed data.

Wind component rms errors computed for the maximum data analyses at each ship's location averaged 6.8 kt. This value may be compared to that of Thomasell and Welsh (1963) who used a screening regression technique to determine the sea-level wind from a number of meteorological variables available from the sea-level pressure and air and sea temperature analyses.

Comparison of these regression wind components to the observed wind components resulted in rms errors of slightly greater than $9 \mathrm{kt}$. The 2 -kt improvement achieved by the results of this study is attributable to knowledge of the wind speed and perhaps to a slight superiority of Cardone's inflow angle formulation over their regression formulation.

In the study described here, verification of the wind components was made where ship observations of wind speed, wind direction and pressure were withheld from the analysis. The rms errors of the wind components computed from the pressure and wind speed analyses were verified against the withheld observations as discussed above. For the analyses computed with $75 \%$ of the observations withheld, the rms wind component errors average $8.7 \mathrm{kt}$, or $1.9 \mathrm{kt}$ greater than the results obtained by use of $100 \%$ of the data. Withholding about $89 \%$ of the ship data yields a further increase in the average rms wind component error of only $0.4 \mathrm{kt}$, while withholding about $94 \%$ of the ship data yields average rms wind component errors of $9.4 \mathrm{kt}$ or an increase of about $2.6 \mathrm{kt}$ over the $100 \%$ data analyses.

The small variation in these rms errors despite the large difference in the amount of input ship data indicates how knowledge of the wind speed field contributes to specification of the total wind vector field. Application of these speeds via the pressure gradient relationship leads to reasonable estimates of the wind direction.

Table 2 summarizes the verification results. It shows that the errors are generally smaller in the summer, probably due to the prevalence of low-speed regimes and corresponding low-magnitude pressure gradients.

Table 3 shows the distribution of rms pressure errors for all 280 maps. The most frequent errors encountered are between 2.1 and $3.0 \mathrm{mb}$ for the $25 \%$ and $11 \%$ of maximum data analyses, and between 3.1 and $4.0 \mathrm{mb}$ for the $6 \%$ maximum data analyses. 
TABLE 2. Summary of verification results. The statistics are computed for all maps analyzed within a given month.

\begin{tabular}{|c|c|c|c|c|c|c|c|c|c|c|c|c|c|}
\hline \multirow[b]{2}{*}{ Month } & \multirow[b]{2}{*}{ Year } & \multirow{2}{*}{$\begin{array}{l}\text { Number of } \\
\text { synoptic } \\
\text { times }\end{array}$} & \multicolumn{4}{|c|}{$\begin{array}{c}\text { Average rms } u \text { - } \\
\text { component error } \\
\text { (kt) } \\
\text { Data density }\end{array}$} & \multicolumn{4}{|c|}{$\begin{array}{c}\text { Average rms v- } \\
\text { component error } \\
(\mathrm{kt}) \\
\text { Data density }\end{array}$} & \multicolumn{3}{|c|}{$\begin{array}{l}\text { Average rms } \\
\text { pressure error } \\
(\mathrm{mb}) \\
\text { Data density }\end{array}$} \\
\hline & & & $\begin{array}{c}\text { All } \\
\text { data }\end{array}$ & $\begin{array}{l}1 / 4 \\
\text { data }\end{array}$ & $\begin{array}{l}1 / 9 \\
\text { data }\end{array}$ & $\begin{array}{l}1 / 16 \\
\text { data }\end{array}$ & $\begin{array}{c}\text { All } \\
\text { data }\end{array}$ & $\begin{array}{l}1 / 4 \\
\text { data }\end{array}$ & $\begin{array}{l}1 / 9 \\
\text { data }\end{array}$ & $\begin{array}{l}1 / 16 \\
\text { data }\end{array}$ & $\begin{array}{l}1 / 4 \\
\text { data }\end{array}$ & $\begin{array}{l}1 / 9 \\
\text { data }\end{array}$ & $\begin{array}{l}1 / 16 \\
\text { data }\end{array}$ \\
\hline April & 1966 & 4 & 6.4 & 8.1 & 9.2 & 9.1 & 7.0 & 8.9 & 10.2 & 10.3 & 2.4 & 3.2 & 4.7 \\
\hline July & 1966 & 9 & 5.6 & 8.0 & 7.6 & 7.6 & 5.5 & 6.9 & 7.1 & 7.1 & 2.4 & 2.6 & 2.7 \\
\hline August & 1966 & 15 & 5.5 & 7.6 & 7.9 & 8.0 & 5.6 & 7.2 & 7.4 & 7.4 & 2.4 & 3.0 & 3.0 \\
\hline December & 1966 & 17 & 7.0 & 9.7 & 9.7 & 10.9 & 7.7 & 9.3 & 10.2 & 10.3 & 3.5 & 4.1 & 4.6 \\
\hline February & 1967 & 25 & 7.7 & 9.6 & 10.0 & 10.5 & 7.4 & 9.2 & 10.0 & 10.3 & 3.4 & 4.0 & 4.6 \\
\hline
\end{tabular}

\section{Sources of error}

Close inspection of the analyses reveals areas where the pressure gradient was grossly under- and overestimated. This can be determined by comparing areas in the data-sparse analyses to the same areas analyzed with a high density of pressure observations. If, in such areas, the wind speeds translate into pressure gradient magnitudes far different from those deduced by the pressure observations at the ships, several explanations can be offered: 1) the wind speeds are unrealistic, 2) the formulation that computes the pressure gradient is in error, or 3 ) the observed pressure gradient is not representative.

The last argument is unlikely to be true whenever there are a number of ships taking independent observations. The second will always be true to a limited extent. Thus, Hasse and Wagner (1970) report a standard deviation in their experimental data of almost $4 \mathrm{kt}$ when inferring geostrophic wind from observed sea surface winds. Moreover, the equations listed in Table 1 represent a series of step functions and thus depart from the smooth continuity inherent in Cardone's (1969) formulation of $U_{19.5} / U_{G}=G^{\prime}\left(U_{G}, T D, L\right)$ especially for very stable regimes (i.e., $T D>1$ ). Also, the introduction of isobar curvature may very well introduce errors rather than eliminate them.

There is good reason to suspect that the wind speed fields used as a principal input to the model in this study were often unrepresentative. The error check used by Cardone often rejects valid ship observations in the vicinity of a rapidly developing cyclone. A poor estimate of the wind vector by an initial guess of the wind in such areas leads to the elimination of all ship observations reporting a speed which differs by more than $20 \mathrm{kt}$ or a direction by more than $50^{\circ}$ from the initial guess. The resulting wind field then reflects the initial guess analysis rather than the real world, and wind speeds may be in error by more than $20 \mathrm{kt}$ or wind directions by more than $50^{\circ}$.

Current investigations by the author are aimed at determining the sensitivity of the overall analysis to the quality of "the "wind speed "data, the ability to convert wind speeds to pressure gradient magnitudes, and the quality and distribution of the ship observations used in the analysis.

\section{Discussion of sample analyses}

Figs. 7-11 each show examples of sea-level pressure analyses based on $100 \%$ and about $6 \%$ of the maximum available data.

Fig. 7, which was hand drawn from the computerspecified grid by grid pressure values, also shows the positions of the ship observations, land boundaries, and some reference latitude and longitude lines. Figs. 8-11 are from charts drawn by the automatic plotting system at the Goddard Institute for Space Studies.

1) Fig. 7. The map based on only about $6 \%$ of the total available ship data nevertheless computed the miminum pressures of the three low systems to within $1 \mathrm{mb}$ of their values on the corresponding $100 \%$ data chart. The strong gradient southeast of the deepest low center was duplicated quite well by the data-sparse analysis. The latter, however, in the absence of any pressure observations, grossly underestimated the gradient in the southwest quadrant of the same system with the result of apparently shifting the southward extending low pressure trough to a more easterly position.

2) Fig. 8. The more easterly of the two lows was deepened by about $10 \mathrm{mb}$ too much in the data-sparse analysis and the central pressure of the other low was estimated to within $4 \mathrm{mb}$. The high in the eastern Pacific matches quite well on the two analyses. The analysis of the southeast and southwest quadrants of the westernmost low demonstrates how a reasonable estimate of the relative pressure gradient magnitudes leads to a good

TABLE 3. The number of analyses whose rms pressure errors are within the specified intervals.

\begin{tabular}{cccc}
$\begin{array}{c}\text { Range } \\
\text { of rms } \\
\text { pressure } \\
\text { error } \\
(\mathrm{mb})\end{array}$ & \multicolumn{4}{c}{ Percentage of data withheld } \\
\hline $\begin{array}{c}5.0 \\
2.1-3.0\end{array}$ & $75 \%$ & $89 \%$ & $94 \%$ \\
$3.1-4.0$ & 32 & 5 & 1 \\
$4.1-5.0$ & 20 & 27 & 17 \\
$5.1-6.0$ & 5 & 11 & 24 \\
$6.1-7.0$ & 1 & 4 & 14 \\
$\geqslant 7.1$ & 2 & 1 & 2 \\
\hline
\end{tabular}




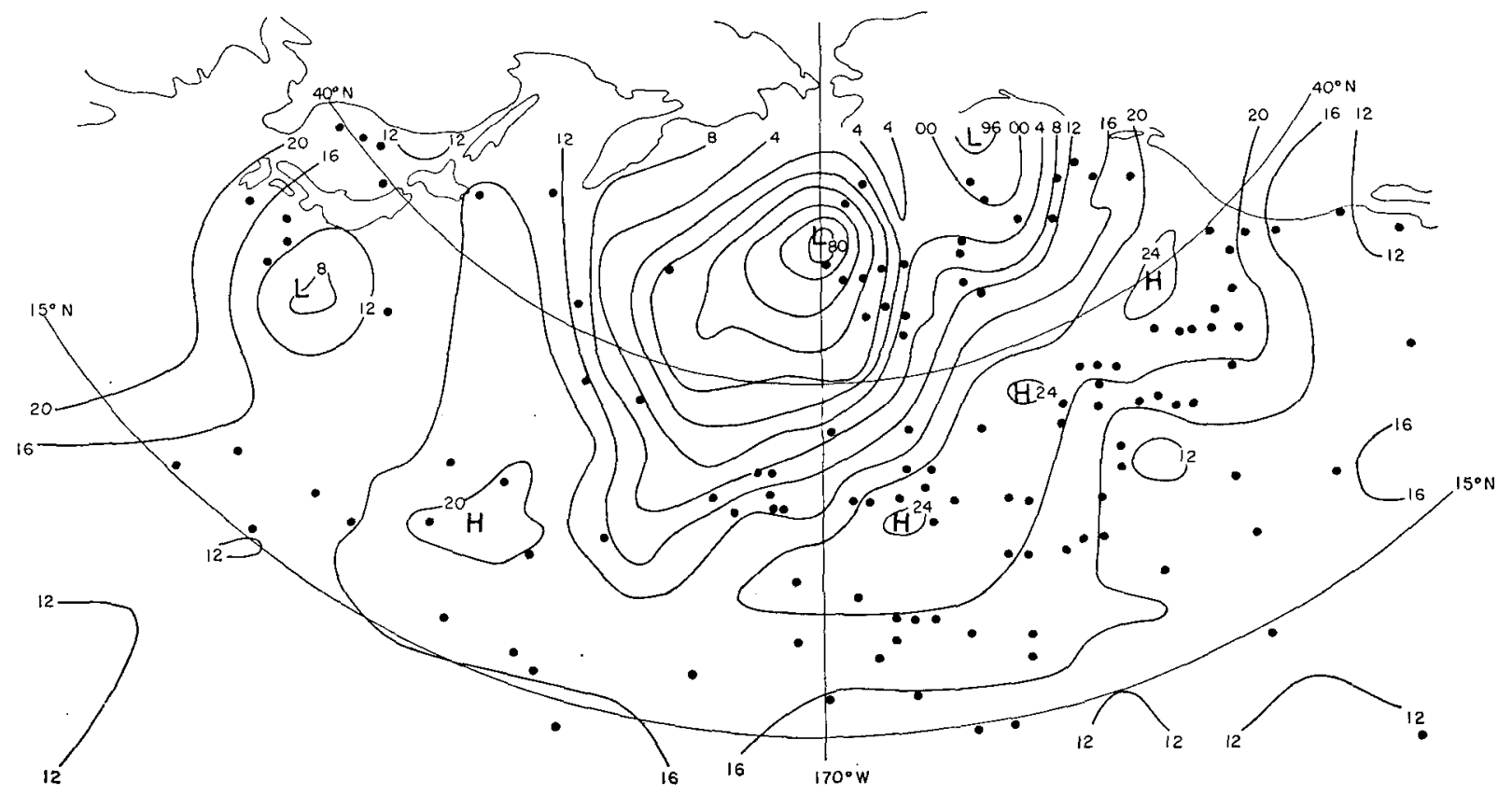

a.

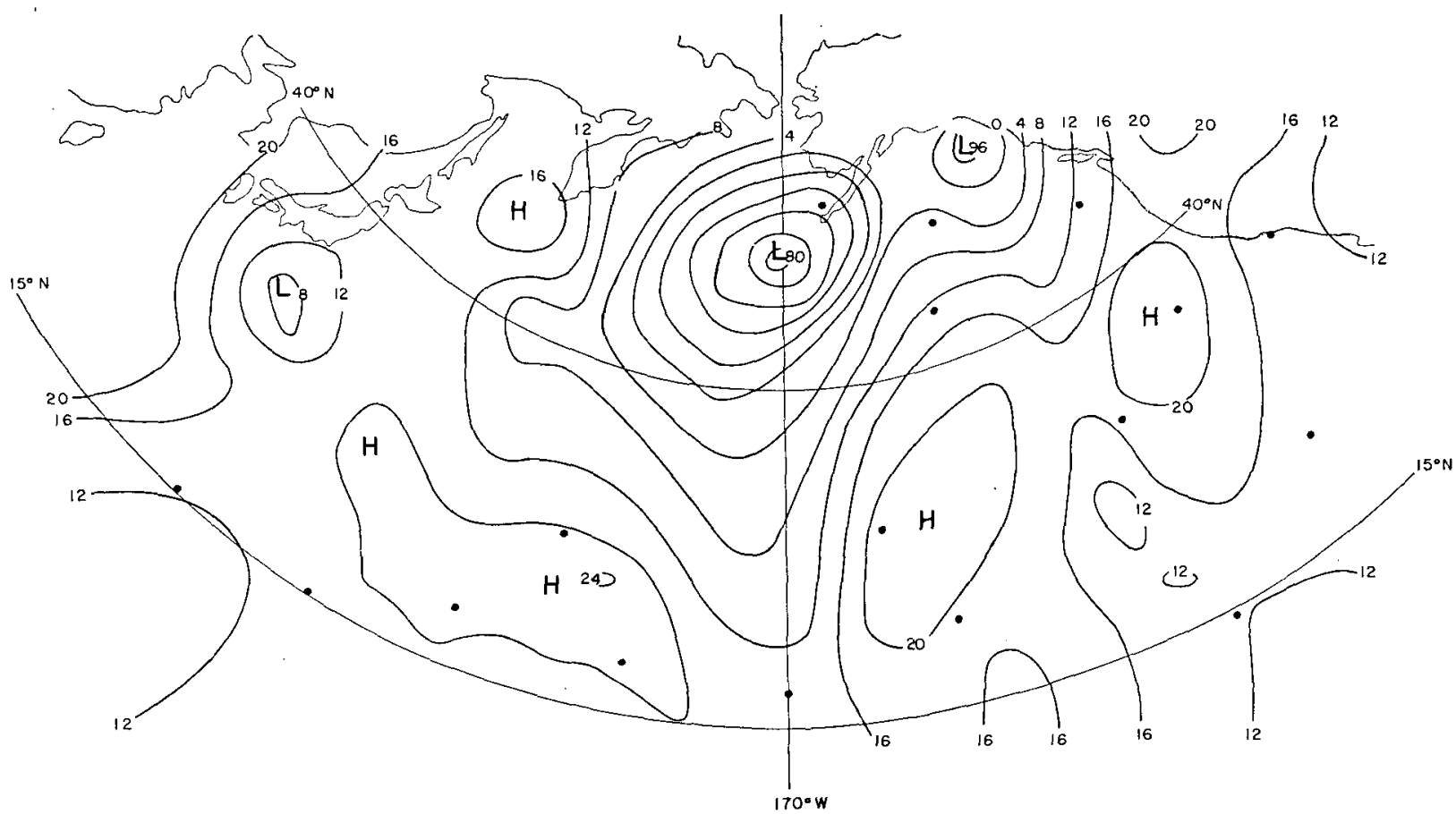

b.

Frg. 7. The all-data (a) and data-sparse (b) sea-level pressure analyses for 0600 GMT 1 April 1966. The dots indicate the locations of the observations used. The rms difference between the pressure fields is $2.9 \mathrm{mb}$.

estimate of the shape of the isobars and hence the wind direction.

3) Fig. 9. The proximity of two of the lows to the upper boundary (where pressures are known) has lead to accurate estimates of the central pressures.
4) Fig. 10. Very strong pressure gradients are in evidence on this map and they have successfully been matched by the data-sparse analysis for the most part. The apparent shift in the position of the easternmost low pressure center may be due to the fact that the 


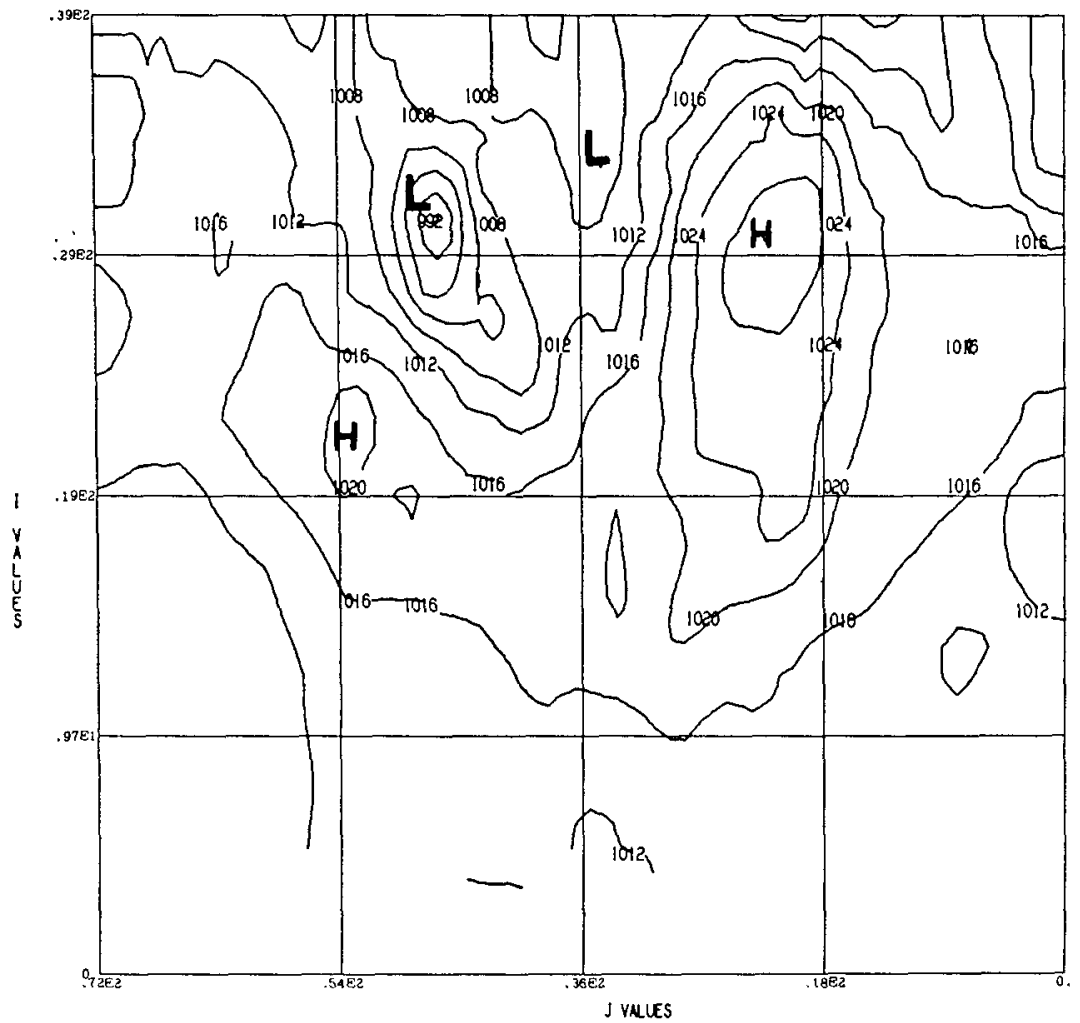

a.

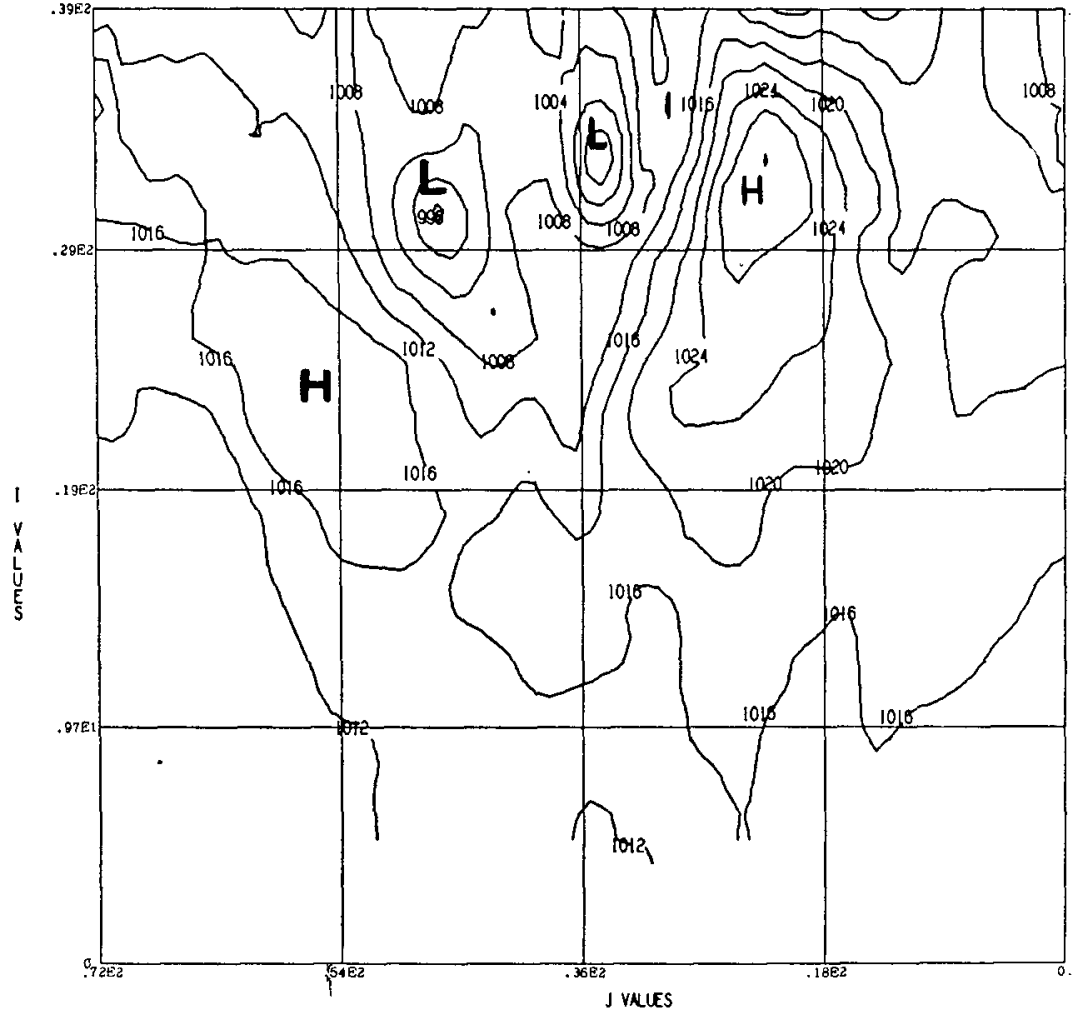

b.

FIG. 8. The all-data (a) and data-sparse (b) sea-level pressure analyses for 0000 GMT 10 July 1966. The rms difference between the pressure fields is $2.1 \mathrm{mb}$. 


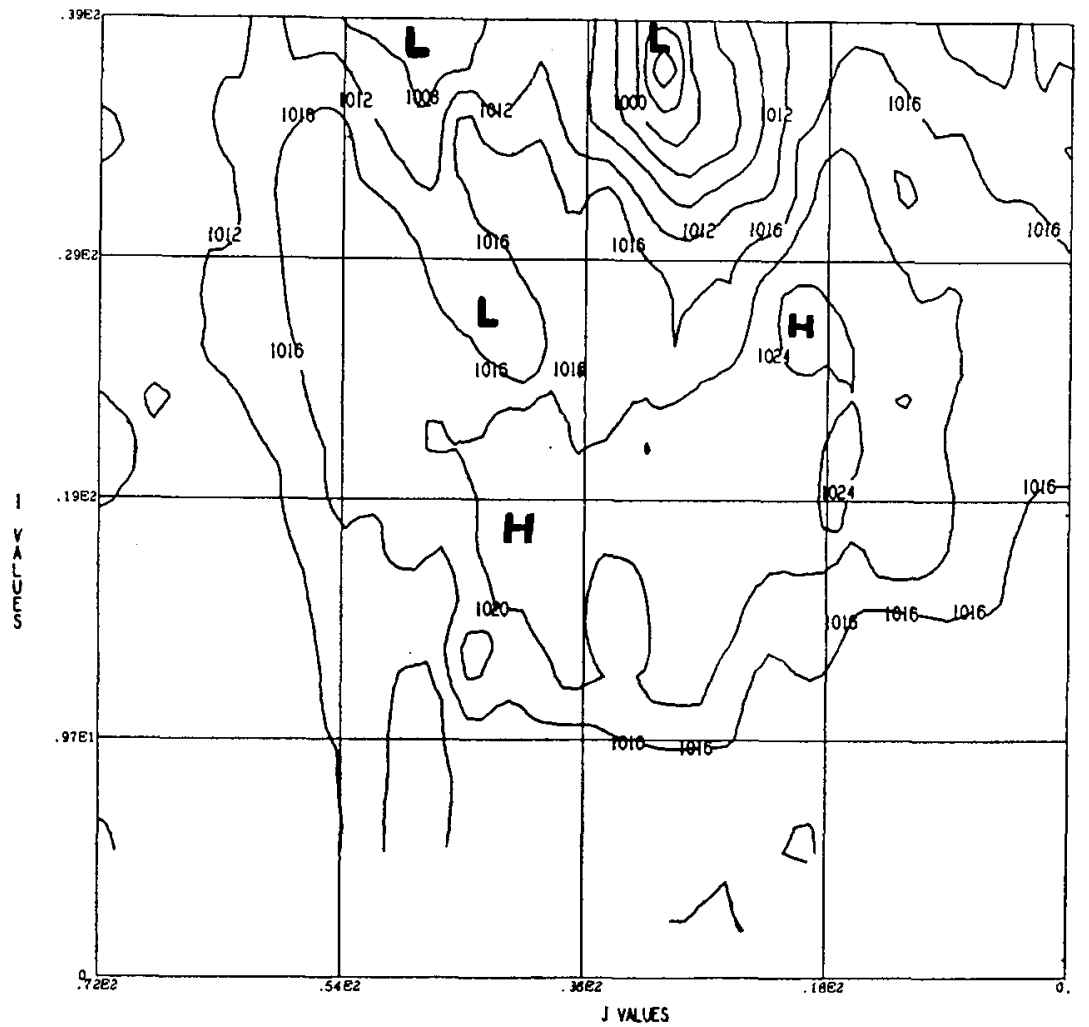

a.

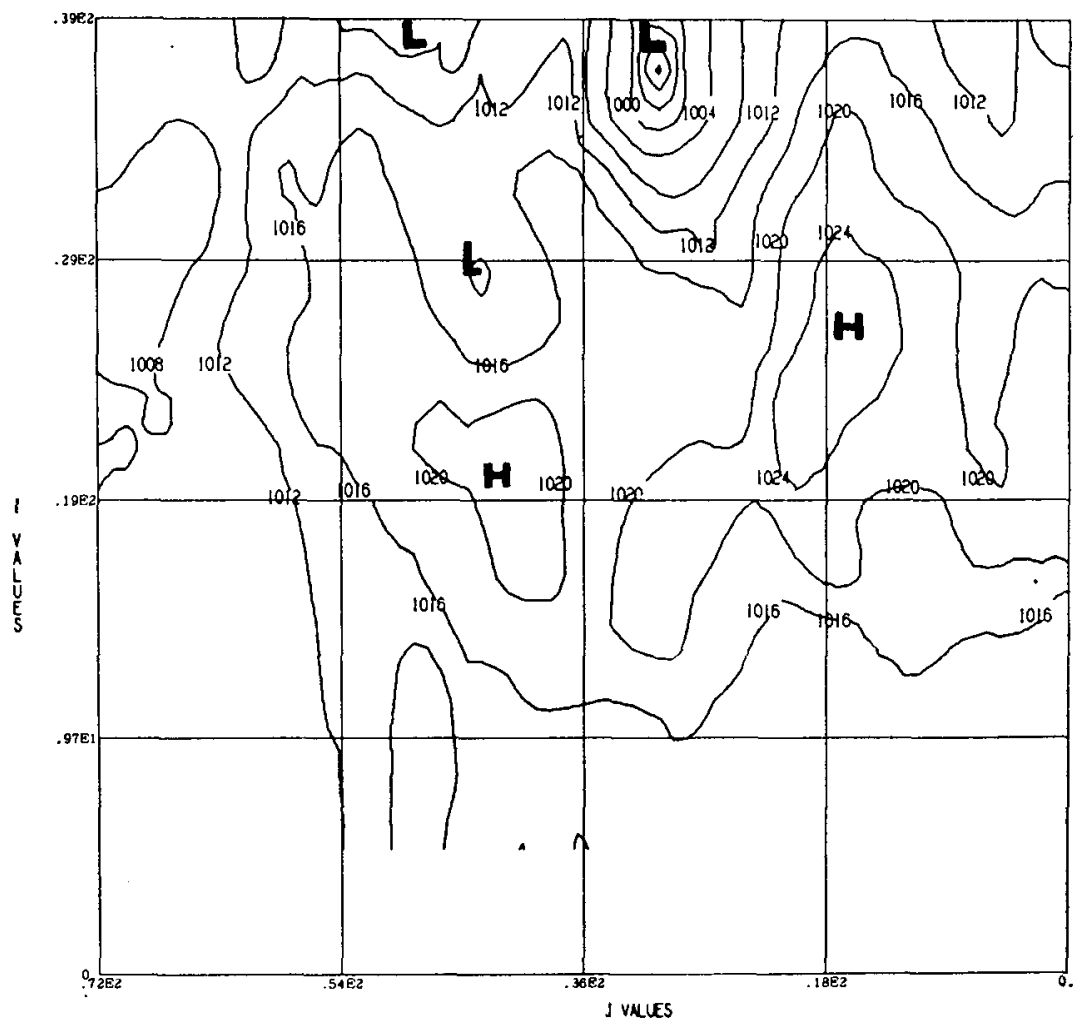

b.

FIG. 9. The all-data (a) and data-sparse (b) sea-level pressure analyses for 0600 GMT 31 August 1966. The rms difference between the pressure fields is $1.8 \mathrm{mb}$. 


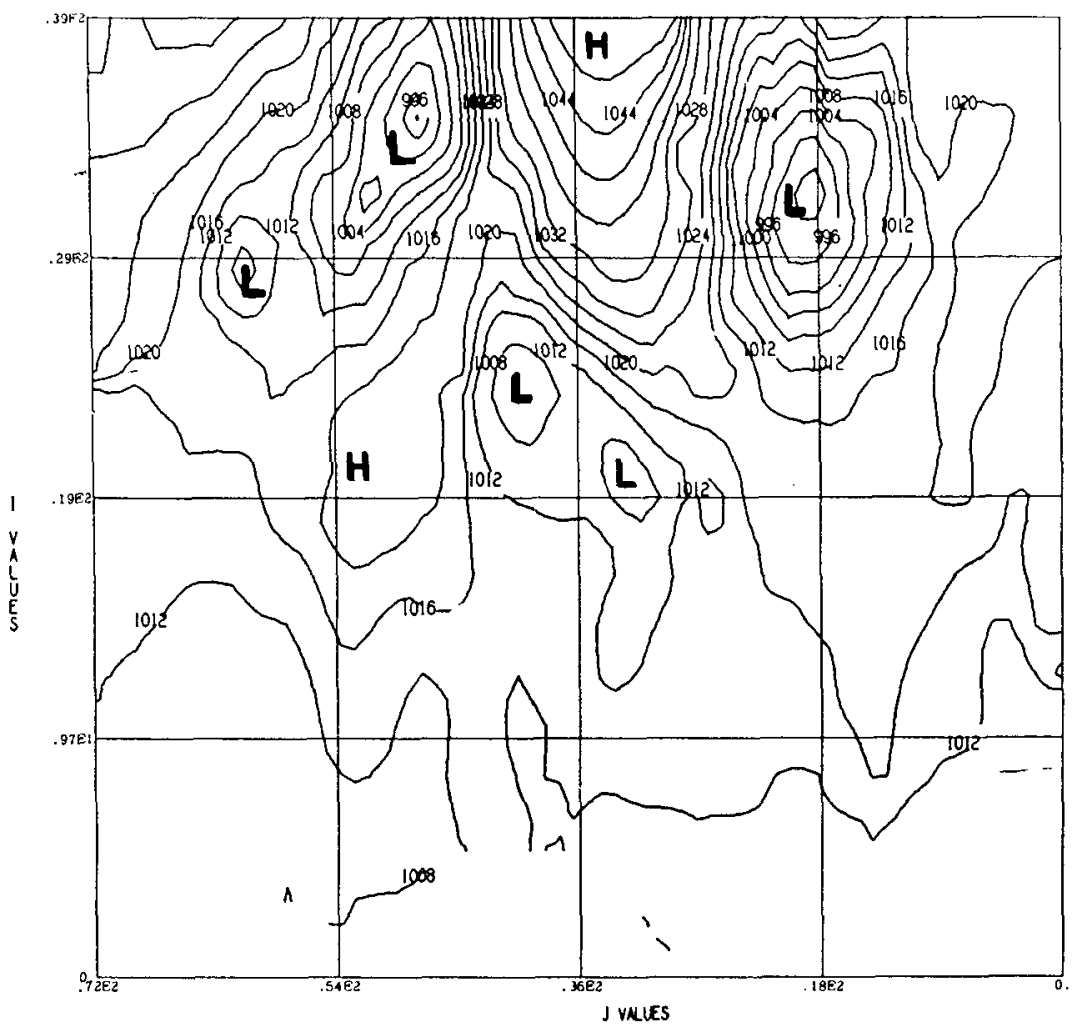

a.

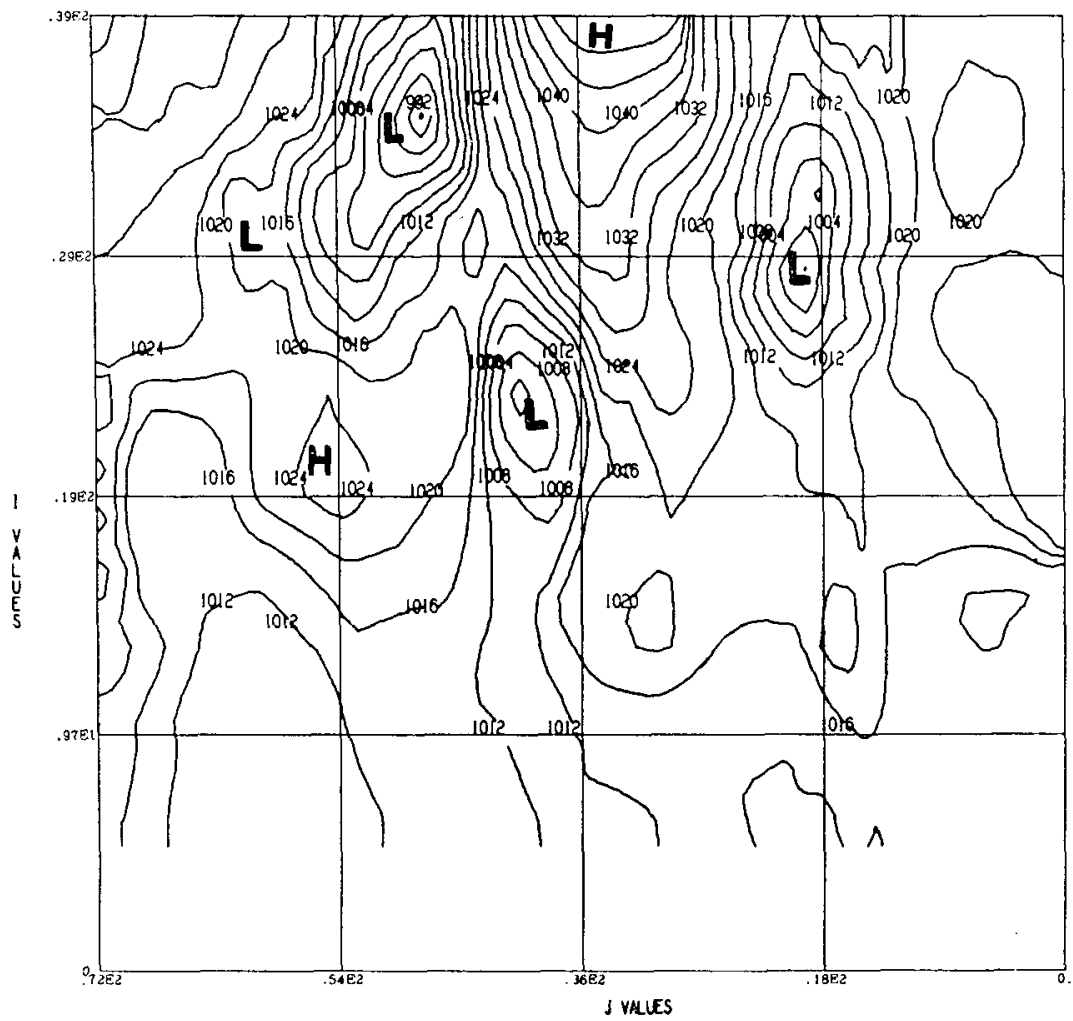

b.

FIg. 10. The all-data (a) and data-sparse (b) sea-level pressure analyses for 0000 GMT 1 December 1966. The rms difference between the pressure fields is $4.0 \mathrm{mb}$. 


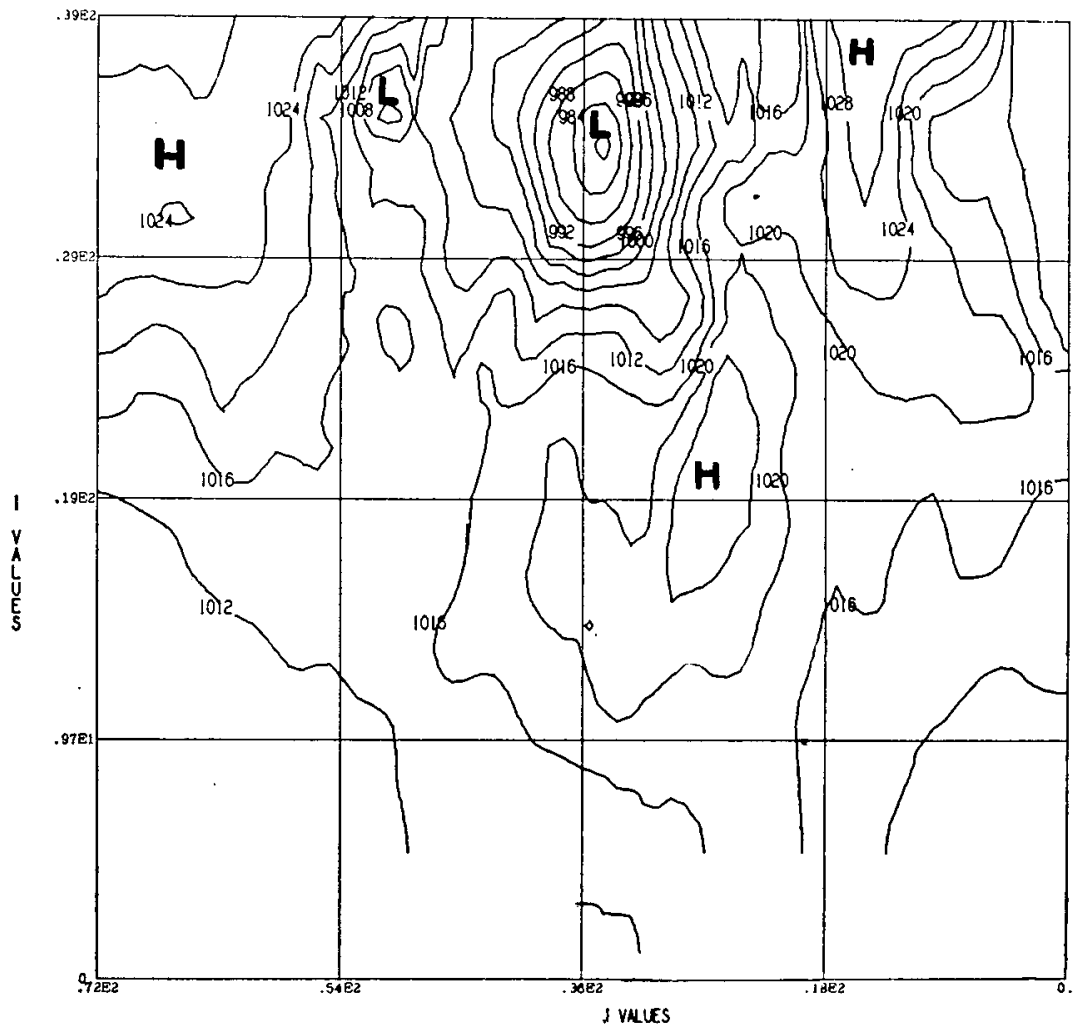

a.

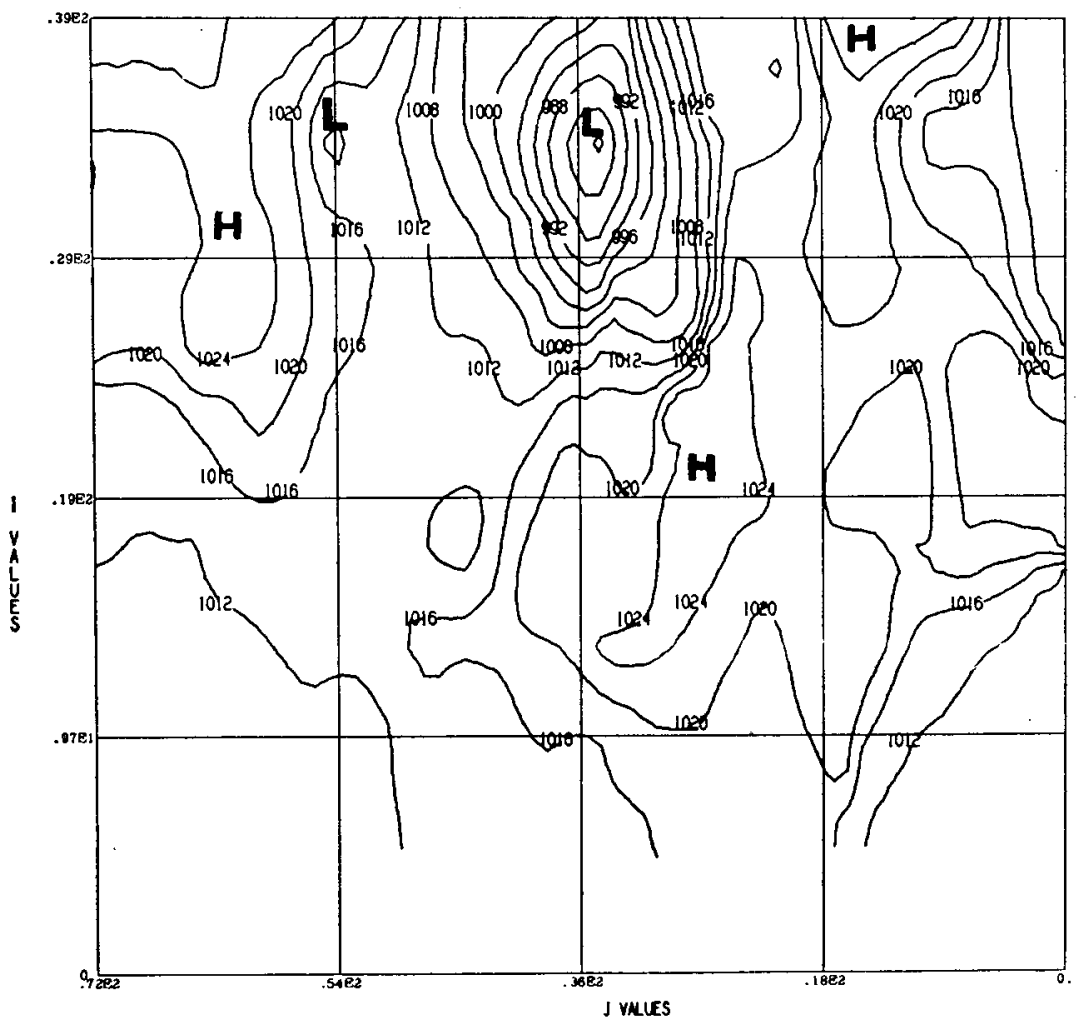

b.

FIG. 11. The all-data (a) and data-sparse (b) sea-level pressure analyses for 0000 GMT 20 February 1967 . The rms difference between the pressure fields is $2.5 \mathrm{mb}$. 
model was given the location of the center as it appears on the all-data analysis with a central pressure of about $990 \mathrm{mb}$. The data-sparse analysis, however, estimated a central pressure at that location of about $999 \mathrm{mb}$. On both charts the pressure just to the south of the specified center is as low as $996 \mathrm{mb}$, thus causing an apparent southward shift in the location of the center on the data-sparse chart. Although such an overestimate of a pressure minimum can cause a shift such as described above, it is not likely to happen often because the estimate of central pressure is dependent on the very same observations of pressure that also determine the surrounding analysis; the estimate does, however, often reflect the observations at several ships in different directions from the center or the pressures at the northern boundary and thus may infrequently seem incongruous with the analysis determined in the vicinity of any one nearby observation.

5) Fig. 11. Many of the features associated with the deep low center have been matched in the two analyses. However, the less intense low has been shallowed in the sparse analysis.

It is difficult to generalize the model's performance beyond what has been already mentioned because the analyses are derived from a random selection of the total available data; the sparse distribution of input data is therefore different in each example. The analysis is undoubtedly affected by the distribution and quality of the selection. It may, however, be safely assumed that the accuracy of, say, the mean pressure over the entire field is sensitive to the accuracy of the few observations of pressure available to it, whereas the determination of the shape of the isobars (i.e., the wind direction) depends as much on the specification of the wind speed field and the translation of that information into estimates of the pressure gradient magnitude.

\section{Conclusions}

The verification of the pressure and wind fields generated by the model demonstrates the applicability of voluminous wind speed data such as would become available from an operational radar-radiometer system to meteorological analysis in the marine boundary layer.

The model uses simulated satellite-derived wind speeds in combination with conventional data from ocean-going vessels. Single-station analyses about the several pressure observations are extended outward so that the pressure gradients reflect the known values of the wind speed. Similarly, the pattern of increasing pressures away from a low pressure center (whose location can be deduced from continuity or satellite photography) can be computed by allowing initially concentric isobars to deform so that the pressure gradients adjust to the known wind speeds.
The pressure gradient magnitudes were computed by inverting the wind-pressure relationships developed by Cardone (1969), with isobar curvature being used after the first iteration of the pressure field to modify the computed pressure gradients. Further work should be done to determine how trajectory curvature might be computed from isobar curvature for a better determination of the pressure gradient. Other ageostrophic effects such as isallobaric winds and lateral eddy diffusion forces should also be investigated to determine to what extent they cause departures from the derived $U_{19.5}$ vs $U_{G}$ wind equations.

The simulation of the satellite wind speeds from objective wind analyses limits the results in that inconsistencies between the wind field and the observed pressure gradient are often evident. This limitation should, however, be alleviated by the proposed satellite system in that wind speeds more representative of synoptic time and space scales are anticipated.

Verification of the pressure fields that were analyzed by deleting $75 \%$ of the maximum available conventional meteorological data showed an average improvement in the rms pressure error of almost a millibar over objective analyses made at a comparable data density in another study. Withholding an additional $19 \%$ of the conventional data resulted in a further increase of only $1 \mathrm{mb}$.

The magnitude of the rms pressure errors, which averaged 3.0-4.0 mb, implies that the pressure fields can be successfully combined with SIRS (Satellite Infrared Spectrometer) observed temperature profiles to improve the specification of upper level pressure surfaces.

Errors in the $u$ and $v$ components of the wind, as deduced from the sea-level pressure analyses, show only a small sensitivity to variations of data density between $6 \%$ and $100 \%$ of the maximum. The range of average rms errors, 6.8-9.4 kt, compares favorably with results from other previous studies.

Deficiencies in the quality of ships' pressure observations may eventually be partially overcome by the proposed National Buoy Data System. The combination of superior meteorological observations from such a network with voluminous wind speed information from an earth-orbiting satellite will undoubtedly result in even superior sea-level wind and pressure specification. The model could be used to demonstrate this by specifying wind and pressure from a "perfect" analysis at those locations that are designated for the buoys and then following through with an investigation similar to that described herein.

Acknowledgments. The author is indebted to Prof. W. J. Pierson for his continuous interest and guidance throughout the research. Thanks go also to Prof. V. J. Cardone for his encouragement and advice and to Prof. J. Spar who also reviewed the original manuscript. Mrs. Catherine Greenwood's technical assistance facilitated the data processing and Mrs. Gertrude Fisher drafted 
the figures. Computer time and technical assistance made available at the Goddard Institute for Space Studies by Dr. R. Jastrow is gratefully acknowledged.

\section{REFERENCES}

Cardone, V., 1969: Specification of the wind distribution in the marine boundary layer for wave forecasting. GSL Rept. TR-69-1, Dept. of Meteorology and Oceanography, New York University.

Cressman, G. P., 1959: An operational objective analysis system. Mon. Wea. Rev., 87, 367-474.

Hasse, L., and V. Wagner, 1970: On the parameterization of the wind speed at sea. Paper presented at the AIAA/AGU Symposium on Astrodynamics and Related Planetary Sci- ences, Washington, D. C., April 1970 (abstract in Trans. Amer. Geophys Univ., 51, p. 322).

Hollinger, J. P., 1970: Passive microwave measurements of the sea surface. $J$. Geophys. Rev., 75, 5209-5213.

Jastrow, R., and M. Halem, 1970: Simulation studies related to GARP. Bull. Amer. Meleor. Soc., 51, 490-513.

Moore, R., and W. J. Pierson, 1970: Worldwide oceanic wind and wave predictions using a satellite radar-radiometer. AIAA Paper No. 70-310.

Thomasell, A., and G. Northrop, 1970: Results of the environmental models/system effectiveness/scale resolution and pilot model program studies. Tech. Rept. TRC DWN 232, Travelers Research Center, Inc., Hartford, Conn.

_- , and J. G. Welsh, 1963 : Studies in the specification of surface winds over the ocean. Final Rept., Contract 7049-88, Travelers Research Center, Inc., Hartford, Conn. 